\title{
IMPACTOS SOCIOAMBIENTAIS E A PANDEMIA DO NOVO CORONAVÍRUS
}

\author{
M. R. DE O. SILVA ${ }^{1}$, R. C. DO NASCIMENTO ${ }^{2}$, A. R. P. AMARAL ${ }^{3}$ \\ Universidade do Estado da Bahia ${ }^{1,2,3}$ \\ ORCID ID: https://orcid.org/0000-0001-7443-2496 ${ }^{1}$ \\ regina estudante@hotmail.com ${ }^{1}$ \\ Submetido 19/08/2020 - Aceito 05/11/2020 \\ DOI: $10.15628 /$ holos.2020.11015
}

\section{RESUMO}

O presente artigo visa discutir sobre os impactos socioambientais relacionados à pandemia do novo Coronavírus (nome científico Sars-CoV-2), que causam enfermidade Covid-19, refletindo sobre as condições ambientais e sociais causadoras desta doença e sofridas por ela. Para tanto, foi realizada uma Pesquisa Documental e Bibliográfica, abordando orientações produzidas pela Organização Mundial de Saúde (OMS), Programa das Nações Unidas para o Meio Ambiente (PNUMA), Ministério da Saúde do Brasil, e artigos

científicos nas bases de dados Scielo e Google Acadêmico. Com esta pesquisa, evidenciou-se que a propagação do vírus tem a ver com a destruição do meio ambiente e com a circulação de pessoas no mundo globalizado, sendo urgente e necessário proteger os recursos ambientais e o investimento em pesquisas científicaspara evitar a repetição de episódios como o do novo coronavírus, sujeitos a acontecer em um momento futuro, caso não sejam adotadas medidasde menor impacto ao ambiente.

PALAVRAS-CHAVE: Microorganismos. Ecossistemas. Saúde. Antropoceno. Planeta.

\section{SOCIAL AND ENVIRONMENTAL IMPACTS AND THE NEW CORONAVIRUS PANDEMIC}

\begin{abstract}
This paper aims to analyze the social and environmental impacts linked to the pandemic of the new Coronavirus (Scientific name: Sars-CoV-2) which causes the Covid-19 disease and reflect the social and ecological conditions that produce and suffer from the disease. Within that context, documental and bibliographical research has been carried out, addressing guidelines launched by the World Health Organization (WHO), United Nations Environment Program (UNEP), Ministry of Health of Brazil, and several scientific articles Scielo and Google Academic database. The research revealed that the spread of the virus has much to do with the destruction of the environment and the circulation of people all over the globalized world, demanding as
\end{abstract}

urgent and necessary the protection of environmental resources and investment in scientific research to avoid repetition of episodes such as the new coronavirus, subject to repetition in the future if measures of lesser impact to the environment are not duly taken at the moment.

KEYWORDS: Microorganisms. Ecosystems. Health. Anthropocene. Planet. 


\section{INTRODUÇÃO}

A COVID-19 foi declarada "pandemia" pela Organização das Nações Unidas (ONU) em 11 de março de 2020, passando-se a recomendar medidas de afastamento social, a redução de circulação de pessoas e evitar aglomerações para restringir a propagação da doença. No Brasil, antes da OMS declarar a pandemia, a infecção humana pelo novo coronavírus foi declarada Emergência em Saúde Pública de Importância Nacional -ESPIN, em 3 de fevereiro de 2020 (Brasil, 2020a).

O Coronavírus recebe esse nome por ter a aparência de uma coroa, daí o nome Coronavírus, que representa um grupo de vírus que afeta humanos, causando sintomas leves de dor de garganta, coriza, tosse, dor de cabeça típico de uma gripe ou resfriado. No entanto, alguns vírus do tipo coronavírus podem desenvolver patologias respiratórias mais graves levando ao óbito, a exemplo do Sars-CoV-2- o novo coronavírus-, que causa a doença Covid-19 (Fioratti, 2020).

Os vírus são microrganismos simples que necessitam de um hospedeiro para realizar seu metabolismo. No caso do novo coronavírus, ele pode se manter ativo tanto no ser humano vivo como no cadáver, ainda que por poucos dias, motivo pelo qual recomenda-se o isolamento dos corpos após a morte (Brasil, 2020b).

Acredita-se que a pandemia do novo coronavírus deu-se por conta da retirada de animais selvagens do seu meio natural para o ambiente urbano para fins de comercialização, em um mercado sem condições de higiene e sem uma vigilância sanitária adequada, na cidade WuhanChina (Fioratti, 2020).

Os vírus têm ocasionado doenças de saúde pública que trazem grandes preocupações e prejuízos à humanidade, a exemplo das doenças virais surgidas nos últimos 20(vinte) anos como o coronavírus da Síndrome Respiratória Aguda Grave (SARS-CoV) em 2002 a 2003; a influenza H1N1 em 2009 e o coronavírus da Síndrome Respiratória do Oriente Médio (MERS-CoV), com origem na Arábia Saudita em 2012 (Cascella, 2020).

Frente a essas considerações, foi realizada uma Pesquisa Documental e Bibliográfica em fontes normativas sobre a Covid-19 e em bases de dados Scielo e Google Acadêmico com o objetivo de apresentar discussões sobre os impactos socioambientais ocasionados pela pandemia do novo Coronavírus (nome científico Sars-CoV-2), que causa a enfermidade Covid-19, refletindo sobre a relação da pandemia com as condições ambientais e sociais alteradas e sofridas pelo ser humano, a importância do sistema de saúde, da ciência e da tecnologia frente ao cenário atual, as prováveis lições resultantes da vivência da pandemia e possíveis soluções para evitar que fenômenos iguais repitam-se no futuro.

\section{IMPACTOS SOCIOAMBIENTAIS E A PANDEMIA DO NOVO CORONAVÍRUS}

Há mais de dez anos, um grupo de pesquisadores da China já havia alertado sobre a grande quantidade de coronavírus nos morcegos, o que, em associação ao hábito cultural de se comer mamíferos silvestres no sul da China, era algo potencialmente perigoso para o meio ambiente 
humano (Cheng et al., 2007). De acordo com pesquisa, morcegos (Chiroptera) sejam os prováveis hospedeiros originários do coronavírus, sendo os Sars-CoV-2 encontrados também em pangolins malaios, animal de hábito alimentar dos chineses, prováveis hospedeiros do vírus transmitido ao ser humano, causador da COVID-19 (Lam et al., 2020).

Acredita-se que o novo Coronavírus passou por mutações, desde epidemias anteriores a esta, como a Síndrome Respiratória Aguda Grave (SARS) na Ásia e a Síndrome Respiratória do Oriente Médio (MERS) (Senhoras, 2020), que acometeu milhares de pessoas nessas regiões.

Embora ainda existam muitas incertezas quanto ao conhecimento sobre a Covid-19, é certo que o contato do ser humano com animais selvagens ou rebanhos o expõe a disseminação de seres vivos causadores de doenças (patógenos), classificadas como zoonoses, doenças transmitidas entre animais e seres humanos (Figura 1), podendo ter como agentes que desencadeiam essas patologias microrganismos diversos, como vírus, bactérias, fungos, entre outros, e surgem em decorrência das transformações do meio ambiente pelo ser humano. A destruição de espaços naturais coloca elementos da fauna e da flora que abrigam microrganismos causadores de doenças em contato com o ser humano, dando oportunidades deste contrair doenças (PNUMA, 2020).

o que são zoonoses e qual a sua prevalência?

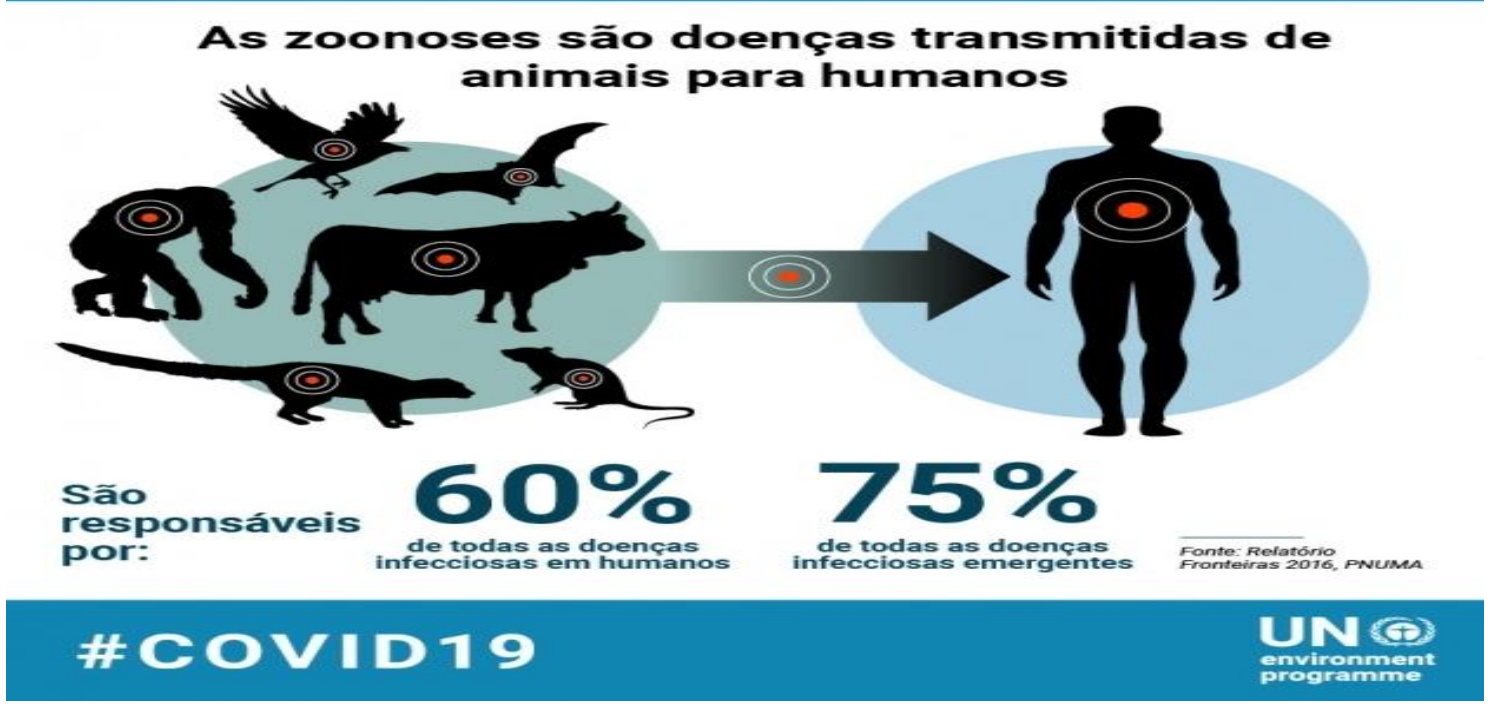

Figura 1: Caracterização das zoonoses Fonte: Relatório Fronteiras-PNUMA (2016).

Cerca de $60 \%$ das doenças infecciosas humanas e $75 \%$ das doenças infecciosas emergentes são zoonóticas, ou seja, transmitidas através de animais, a exemplo de doenças recentes como ebola, gripe aviária, a Síndrome Respiratória do Oriente Médio (MERS), o Vírus Nipah, a Febre do Vale Rift, a Síndrome Respiratória Aguda Grave (SARS), a Febre do Nilo Ocidental, o vírus zika e, agora, o coronavírus, todos ligados à atividade predatória do meio ambiente pela espécie humana (PNUMA, 2020).

As doenças associadas aos morcegos, a exemplo da Covid-19, surgiram pelo desmatamento e produção agrícola, tirando esses animais do seu habitat natural, desintegrando o ecossistema natural, em que esses animais têm papéis de polinizadores noturnos e predadores de insetos (PNUMA, 2020), benefícios estes desconsiderados por seres humanos que reagem diante de 
pandemias matando o animal hospedeiro do patógeno causador da doença (Vale \& Prezoto, 2017; Andrade, 2020).

A Covid-19 é uma doença emergente, que envolve as relações da espécie humana com a natureza. Microrganismos causadores de doenças como os coronavírus causam e ainda poderão causar surtos graves em um futuro próximo para os quais ainda não existem soluções preventivas, curativas ou insuficientes, sendo, o desafio, a manutenção das reservas ambientais e do patrimônio cultural das populações (Chaves \& Bellei, 2020).

Fatores como a facilidade do deslocamento humano, a destruição de ambientes naturais, gerando o deslocamento de animais para outros espaços urbanos em contato com humanos,e a produção animal para alimentação humana contribuíram para a disseminação de microrganismos patógenos como o Sars-CoV-2, gerando uma oportunidade para se pensar e buscar uma Saúde Única, que envolve as interações entre saúde ambiental, animal e humana, como elemento chave para entender muitas doenças emergentes (Chaves \& Bellei, 2020).

De acordo com Amaral (2020), há uma relação indissociável entre a destruição do meio ambiente, a superação das fronteiras que sempre existiram entre o homem e o meio ambiente e a capacidade de que certos vírus desconhecidos possam afetar as relações humanas, sendo urgente e necessário proteger o meio ambiente para evitar a repetição de episódios como o do coronavírus.

A saúde pública requer uma condição ambiental adequada para oferecer os elementos mínimos de sobrevivência ao ser humano, como alimento, ar, água, chuva, energia, calor, paisagismo, solo, entre outros (Andrade, 2020). Nesse sentido, a saúde humana depende das condições ambientais salubres. Isso evita a sobrecarga das unidades de saúde. Quanto melhor o cenário socioambiental, menor é a quantidade de enfermidades. Na visão de Ventura (2020), a resposta às emergências só é possível através de sistemas de saúde bem estruturados, com capacidade de vigilância e de pesquisa, conduzidos por profissionais críticos, bem formados e capacitados.

A pandemia do novo coronavírus mostra que o sistema de saúde não está preparado para dar uma resposta satisfatória à demanda da sociedade, como vem ocorrendo cotidianamente. $\mathrm{Na}$ visão de Cueto (2020, p.6), "As repostas insuficientes a esta pandemia são o resultado de anos de respostas insuficientes aos problemas de saúde como um todo".

O mesmo autor aponta como um dos fatores para isso, a política neoliberalista implantada nos países a partir da década de 1980. Privatizar a saúde alegando que proporcionaria bem estar para todos, provou-se diferente. Em uma epidemia como a que ora ocorre, é o sistema público de saúde que deve dar uma resposta satisfatória à sociedade. Não estando preparado, acaba perdendo vidas por conta da sua precariedade (Cueto, 2020). Uma medida muito significativa seria adotar a sustentabilidade no campo da saúde global (Antunes, 2020).

O modelo predatório de relação que o ser humano estabelece com o meio ambiente, pautado na ideia e comportamento de infinitude dos recursos naturais, leva o sistema natural ao colapso, trazendo danos para os seres vivos, principalmente para a espécie humana, demonstrando 
que as consequências do mal gerenciamento dos recursos chegam e ainda chegarão de forma desastrosa se não houver uma trégua à devastação ambiental.

Um ecossistema íntegro proporciona saúde e bem estar humano; ajuda a controlar doenças; mantém a biodiversidade e constitui barreira para a disseminação de agentes causadores de doenças. A COVID-19 mostra que não é mais possível conviver com esse modelo predatório do meio ambiente; é necessário uma reconstrução da sociedade com alternativas sustentáveis e resilientes (PNUMA, 2020).

Além do impacto na saúde, outra questão bastante discutida nos dias de restrições por conta da pandemia é sobre a abertura do comércio. Há uma forte pressão por parte dos comerciantes sobre a administração pública para a abertura desse setor. No entanto, há de se considerar que desenvolvimento econômico requer, antes de tudo, vida humana.

Não há sentido impulsionar a economia, se não há pessoas para fazerem uso dos bens e serviços produzidos. Na visão de Andrade (2020), a prosperidade econômica não pode pautar-se na infinitude dos recursos naturais, pois corre-se o risco de não haver humanos para impulsionar a economia. Como consequência lógica, ocorrendo a crescente exploração dos recursos naturais em prol do desenvolvimento do comércio, não haverá condições para a vida humana na terra.

Outra questão bastante conflituosa é a supremacia do interesse econômico sobre o desenvolvimento da ciência e pesquisa, como o que aconteceu nos Estados Unidos, em que os pesquisadores tinham uma vacina pronta contra um tipo de coronavírus em 2016, mas o projeto foi abandonado porque o Instituto Nacional de Saúde dos EUA alegou que não estava mais interessado porque havia outros interesses econômicos; há necessidade de investimentos cada vez maiores nas áreas de ciência e pesquisa em todo o mundo, visto que soluções mais rápidas ocorrem quanto maior número de pesquisadores estiverem trabalhando nos mesmos problemas (Navas, 2020).

Antunes (2020) defende a ideia de que é fundamental a pesquisa permanente e contínua, levando em conta não apenas a evolução de doenças específicas enquanto elas estão em manchete e causam pânico. Além disso, que investiguem o impacto das crises sobre a saúde das populações e das causas sociais, ambientais, econômicas e políticas das epidemias.

Apesar de não haver, até o presente momento, um tratamento certo ou cura para a COVID19, há uma enorme solidariedade entre cientistas e institutos de pesquisa, com trocas de informações sobre a doença, o que talvez ajude na descoberta da solução para o problema, seja na prevenção (vacina) ou na cura após o contágio, embora haja descrédito à ciência e obstáculos políticos por parte de alguns países, como por exemplo, a xenofobia contra a China (Cueto, 2020; Cascella, et al., 2020).

Enquanto a cura não chega, pode-se reduzir as chances de se infectar ou espalhar a Covid19 tomando algumas precauções simples, como: limpar regularmente e completamente as mãos; manter pelo menos 1 metro de distância física entre as pessoas; evitar tocar nos olhos, nariz e boca; seguir uma boa higiene respiratória; ficar em casa e se auto-isolar, mesmo com pequenos sintomas; se tiver febre, tosse e dificuldade em respirar, procurar atendimento médico, mas ligar com antecedência; seguir as instruções da autoridade de saúde local; manter-se atualizado sobre as 
informações mais recentes de fontes confiáveis, como a OMS ou suas autoridades de saúde locais e nacionais (OMS, 2020).

A OMS (2020) defende a ideia que as duas formas mais efetivas de evitar a contaminação pelo coronavírus é lavar as mãos e ficar em casa. Posteriormente, passou a recomendar o uso de máscara por toda a população, advertindo, no entanto, que as máscaras caseiras não barram gotículas suspensas no ar com o vírus, mas evitam que o espirro libere gotículas contendo os vírus, já que é uma proteção para não deixar as gotículas saírem.

O tipo de máscara mais complexa é feita com três camadas: a mais próxima do rosto feita de algodão; a segunda de TNT (tecido utilizado em aventais hospitalares); e a última de algum tecido sintético resistente a fluidos, como o chiffon. Para o grupo de risco, formado por maiores de 60 anos e portadores de doenças crônicas, recomenda-se uma máscara tipo N-95, usada em hospitais, e que barra os vírus vindos do ambiente (Fioratti, 2020 apud OMS, 2020).

Além dos cuidados com a saúde, a pandemia do novo coronavírus deixa várias lições: sobre a relação humana e meio ambiente, a importância de se desenvolver uma relação cooperativa, harmoniosa e possível, pois a sobrevivência humana depende de ações coletivas, sendo que os impactos gerados em uma região podem facilmente se espalhar para outras; a importância das pesquisas científicas; o quanto se pode fazer em casa, diminuindo a necessidade do uso de veículos automotores terrestres e, consequentemente, menos trânsito nas cidades; uma reflexão sobre as relações sociais e o quanto estas são importantes para a humanidade (Andrade, 2020).

\section{O SISTEMA DE SAÚDE PÚBLICA DO BRASIL E O NOVO CORONAVÍRUS}

No Brasil, o primeiro caso de Covid-19 aconteceu no estado de São Paulo, no dia 26 de fevereiro de 2020. Tratava-se de um idoso que morava em São Paulo, contraiu o vírus quando retornou de uma viagem da Itália. No dia 17 de março de 2020, ocorreu o primeiro óbito por Covid19, também no estado de São Paulo. Depois de um mês da confirmação do primeiro caso do coronavirus, a doença avançou rapidamente por todas as regiões do país iniciando a transmissão comunitária (Alonso et al., 2020).

Quando a pandemia da Covid-19 chegou ao Brasil, a maioria dos casos foi importada de outros países com grande incidência da doença. Assim, a Organização Mundial da Saúde (OMS) estabeleceu medidas restritivas para conter a epidemia, como o isolamento dos casos e contatos físicos, com o objetivo de evitar a transmissão do vírus de pessoa para pessoa e assim evitar a contaminação e transmissão direta. Depois que o vírus passou a circular, houve um aumento no número dos casos, sendo adotadas estratégias de mitigação para evitar a propagação de novos casos e de óbitos pela doença (Oliveira et al., 2020).

De acordo com Werneck e Carvalho (2020), no Brasil, o fator que mais interfere na qualidade de vida da população e gera doenças são as condições precárias de habitação, falta de saneamento básico, no qual observa-se que em muitas casas ainda não há acesso a água encanada e tratada, e em outras residências há situação de aglomeração de moradores, visto que essas pessoas, em sua 
grande maioria, têm poucos recursos financeiros e terminam habitando em lugares insalubres, dificultando a higiene ambiental e pessoal, ocasionando doenças de ordem higiênica e respiratória.

A população brasileira, em sua grande maioria, encontra-se em situação de extrema vulnerabilidade social, com altas taxas de desemprego, com a redução dos investimentos em saúde e nas políticas sociais, prejudicando a população mais carente. Depois da aprovação da Emenda Constitucional no 95/2016, que impôs o teto radical de gastos públicos e com as políticas econômicas implantadas pelo atual governo, houve uma redução de gastos com saúde e pesquisa no Brasil. Neste momento de crise, percebe-se a importância nos investimentos em ciências, saúde e tecnologia, que precisam ser fortalecidos para que o Sistema Único de Saúde (SUS) garanta o direito universal à saúde e à vida (Werneck \& Carvalho, 2020).

O corte de recursos na área de saúde tem dificultado o tratamento dos casos da Covid-19 por falta de leitos, unidade de terapia intensiva (UTI) e equipamentos, déficit no número dos profissionais da saúde. Além disso, cogita-se o desmonte do sistema público de saúde que irá sobrecarregar os trabalhadores e infringir o direito à saúde dos cidadãos, que acabam se aglomerando nas filas dos hospitais e unidades de saúde para receber cuidados (Ministério da Saúde, 2020).

Os impactos socioambiental e econômico são alguns fatores gerados pela pandemia do coronavírus, os quais têm causado preocupações em todas as esferas da sociedade, suscitando questões humanitárias sobre quais estratégias os países carentes de infraestrutura nas áreas de saúde, educação e social devem criar ou programar para poder traçar planos tecnológicos, com o intuito de desenvolver pesquisas cientificas nas áreas de saúde, a exemplo do continente asiático, que atua no desenvolvimento de pesquisas com o objetivo de descobrir medicamentos eficazes no tratamento ou na cura ou prevenção desta pandemia. O aumento nos casos da Covid-19 deve-se à ausência de uma vacina ou outra terapia eficaz que evite o ressurgimento, evitando riscos futuros de se contrair o vírus (Walker et al., 2020).

O Sistema Único de Saúde (SUS) é considerado como um dos maiores sistemas de saúde pública e universal do mundo, que tem um papel preponderante na vigilância e na assistência à saúde, assim como no ordenamento e articulação das ações de enfrentamento à pandemia, nos três níveis de gestão: municipal, estadual e federal. Entretanto, a pandemia do novo coronavírus está sendo um dos fatores que expôs as fragilidades estruturais do SUS e apontou que a falta ou má distribuição dos profissionais da saúde nas diferentes regiões do país, na média e alta complexidade, assim como a capacidade limitada de produção e realização de testes diagnósticos têm afetado os órgãos e sistemas de saúde no país (Oliveira et al., 2020).

\section{POR QUE UMA PANDEMIA EM 2020?}

A destruição ecossistêmica causada pelo homem e o surgimento de pestes podem ser interpretadas de diversas formas. No sentido religioso, as enfermidades são atribuídas como castigo de Deus decorrente da desobediência, conforme a citação bíblica: "E então, quando vocês se 
refugiarem nas suas cidades, enviarei a peste para o meio de vocês, e vocês serão entregues nas mãos do inimigo." (Lev. 26:25).

Cientificamente, a disseminação de uma doença infectocontagiosa segue um roteiro de contaminação denominado tríade epidemiológica, formada, primeiramente, pela existência do agente etiológico, caracterizado por um microorganismo (no caso da atual pandemia é o vírus SarsCoV-2); o segundo elemento da tríade é o hospedeiro, que pode ser intermediário ou definitivo (animal ou pessoa infectada) e, não menos importante, o fator ambiental, formado pelo meio suscetível para a proliferação e desenvolvimento da doença, gerando um ciclo de contaminação cada vez maior (Bruhn, 2016).

Dentre outras causas, a propagação mundial do novo coronavírus decorreu de fatores ambientais, socioeconômicos, culturais e a globalização como aspectos interconectados. Assim, a Covid-19 insere-se como consequência de ações antropocêntricas relacionados à exploração da biodiversidade. Para Perrota (2020), as doenças zoonóticas emergentes são compreendidas como uma face do Antropoceno, relacionada ao desequilíbrio da fronteira interespécie, no qual o vírus pula a barreira do seu hospedeiro natural e passa a infectar humanos.

O século XXI é a era de domínio e soberania humana baseados no controle de tudo, exploração e conhecimento definido pelo Antropoceno e reforçado pelo modelo capitalista. O novo coronavírus trouxe à luz reflexões sobre o papel ecológico do Homo sapiens na natureza. Historicamente, a adaptação e evolução da espécie consome cada vez mais fontes naturais, a exemplo da revolução industrial, em que houve o crescimento do uso de combustíveis fósseis e ao aumento da população humana em relação às demais espécies do planeta (Vianna, 2020).

Na década de 1950 foi estimado que a população mundial fosse 2,6 bilhões de pessoas, 5 bilhões em 1987, 6 bi em 1999, 7,7 bi em 2020 (ONU, 2019). Conforme o gráfico 1, em 2050 a estimativa é de 9,7 bilhões e 11 bi em 2100. Isso decorre do aumento da expectativa de vida, porém o relatório enfatiza que as maiores taxas de natalidade são em regiões mais pobres do planeta (ONU, 2019).

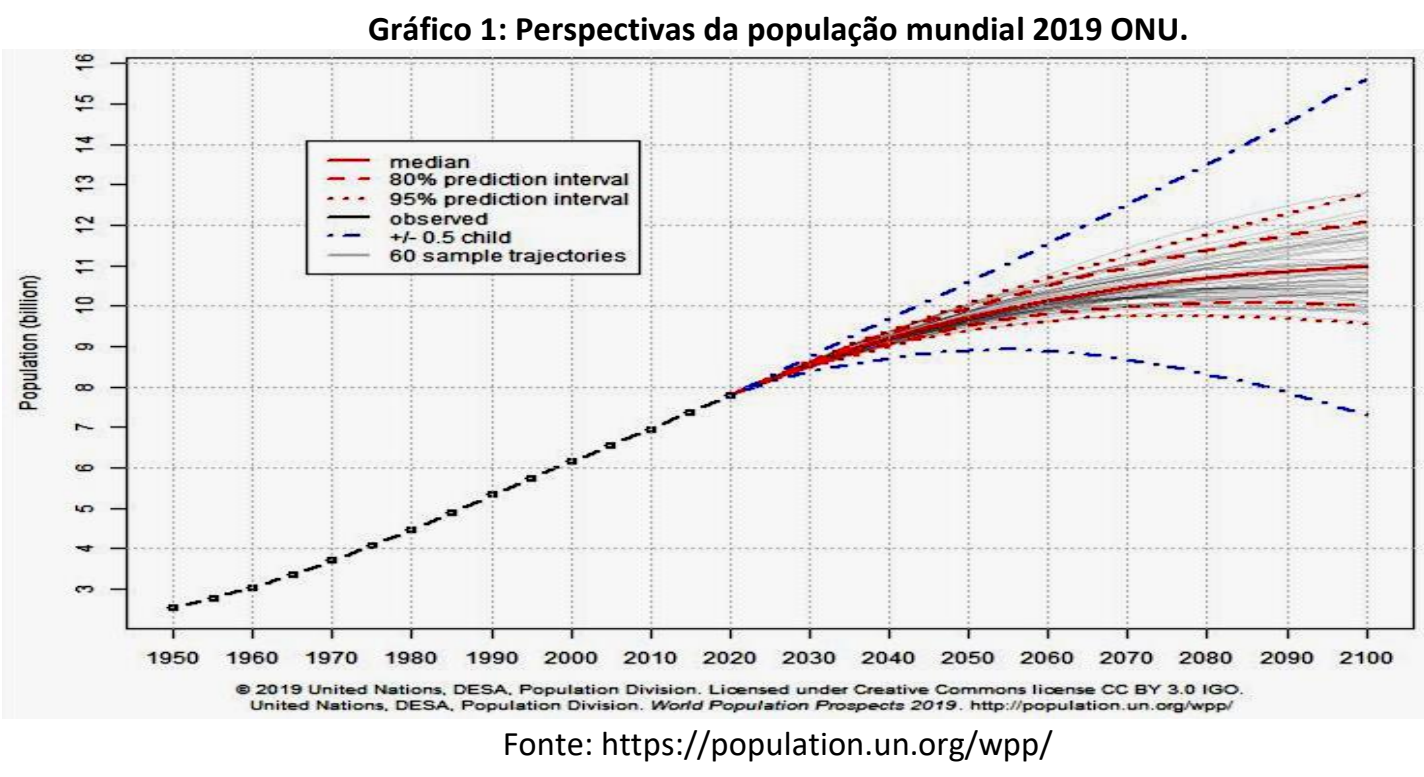


O crescimento demográfico está transformando o planeta em uma "monocultura humana". Dentre os $0,36 \%$ da biomassa terrestre composta pelos mamíferos, $96 \%$ são humanos e animais domesticados. Desse total, gado e porco correspondem a $60 \%$, 36\% humanos e $4 \%$ mamíferos selvagens (Bar-On; Phillips; Milo, 2018). A expansão agrícola, industrial e urbana, oriundas do crescimento populacional, provocou a destruição dos habitats naturais, iniciando a sexta extinção em massa da vida na terra (Vianna, 2020).

Segundo a teoria ecológica Malthusianisma, o aumento demográfico compromete a exploração dos recursos naturais, sendo o crescimento da população humana numa escala geométrica, enquanto os meios de subsistência estão numa escala aritmética (Freitas; Neto; Takenaka, 2017). Assim, quanto mais gente no planeta, mais problemas sociais, ambientais e econômicos haverão de existir.

O aumento da população segue uma escala positiva e contínua, todavia os recursos do planeta terra são finitos, assim, em algum momento, a fome, as pragas e as doenças serão cada vez mais presentes na vida do homem. A luta pela sobrevivência fará com que muitas pessoas se alimentem de forma exótica, como é o caso de comer morcegos, animal que é supostamente o hospedeiro natural do vírus Sars-Cov-2, e o pangolim, possível hospedeiro intermediário do novo coronavírus.

Dessa forma, a intenção desse texto não é encontrar respostas para os dados apresentados, e, sim, abordar discussões e reflexões a partir de teorias ecológicas. A Covid-19 é um exemplo de que o vírus atravessou a barreira interespécie causando destruição ao Homo sapiens. Justamente a espécie que se sente em posição de domínio está sofrendo impactos imensuráveis causados por um pequeno vírus.

Uma das causas do surgimento da pandemia de 2020 pode ser relacionado a superpopulação humana em um curto período de tempo, em detrimento das demais espécies. Ecologicamente, esse fator causa desequilíbrio ao ecossistema, podendo provocar danos às outras espécies. Em ecologia, quando o ambiente está equilibrado, é natural que o meio controle o crescimento de indivíduos através da competição interespecífica (Seneme \& Rachid, 2019).

Partindo-se da analogia entre conceitos epidemiológicos, geográficos e ecológicos, a natureza possui defesas contra o desequilíbrio ambiental, sendo cada vez mais comum a ameaças de doenças à humanidade (Sansonetti, 2020). Por que a espécie humana é a maior vítima das epidemias? A globalização facilitou o acesso às pessoas atravessarem fronteiras em tempo recorde; a migração é uma das formas mais rápidas de disseminação da Covid-19, sendo o isolamento social a medida profilática mais eficaz.

Com os milhões de humanos presos em suas casas, a poluição e os gases do efeito estufa foram reduzidos em diversos países; rios e mares parecem estar mais limpos e a fauna reapareceu em alguns lugares (Ecodebate, 2020). De acordo com a hipótese Gaia, a terra é um organismo vivo e em evolução com capacidade de autorregulação, através do controle do seu clima e temperatura, eliminando seus detritos e combatendo suas próprias doenças (Lovelock, 2020). 
Nesse sentido, a natureza possui suas defesas, podendo ser uma bioterrorista para o controle e equilíbrio da vida. É importante destacar, que não se trata apenas dos impactos causados pelo novo coronavírus, mas das causas que levaram ao surgimento da pandemia, uma vez que os microorganismos fazem parte da biodiversidade, estão constantemente no cotidiano humano e são responsáveis por inúmeras doenças. Uma doença não existe sem a tríade epidemiológica, e é possível ter um ambiente saudável e com menos enfermidades.

\section{CONSIDERAÇÕES FINAIS}

A pandemia do Sars-CoV-2 ou novo coronavírus ocasiona a doença COVID-19. A propagação do vírus tem a ver com a devastação do meio ambiente e com a circulação das pessoas no mundo globalizado. Dessa forma, deve-se levar em consideração que a proteção da biodiversidade também é uma forma de se resguardar a saúde humana. A atual crise de saúde pública ocasionada pela pandemia mostra o quanto o sistema de saúde é frágil e necessita de maiores investimentos em Ciência e Pesquisas em um continuum permanente e prioritário para resolver as emergências antes que elas ocorram.

A biodiversidade que compõe a ecosfera é um sistema fechado entre si, interdependente e vivo, assim, entende-se como um pequeno vírus que surgiu na China se alastrou mundialmente. As tendências demográficas compreendem problemáticas individuais e coletivas, nas quais as doenças transcendem de meios vulneráveis para escalas globais, assim, cuidar do meio ambiente é sinônimo de saúde.

Todos os acontecimentos vivenciados devido ao novo coronavírus podem deixar lições necessárias à adoção de uma nova cultura humana em relação ao meio ambiente, dentro de uma educação ambiental em respeito a todas as formas de vida e de integridade dos ecossistemas e uma cooperação internacional para a busca de uma saúde global. Futuras pesquisas deverão e precisarão surgir em face de muitas questões ainda desconhecidas sobre a COVID-19 e seus impactos a curto, médio e longo prazos

\section{REFERÊNCIAS}

Alcântara, A. (2020). Moradores no Peru estão matando morcegos por medo do coronavírus. Recuperado de: www.polemicaparaiba.com.br/internacional/moradores-no-peru-estaomatando-morcegospor-medo-do-coronavirus-veja-video.

Amaral, A. C. São Paulo já tem melhora na qualidade do ar, diz especialista. Jornal Folha de São Paulo. Recuperado de: https://www1.folha.uol.com.br/equilibrioesaude/2020/03/sao-pauloja-tem-melhora-na-qualidade-do-ar-diz-especialista.shtml?origin=folha.

Andrade, W. Coronavírus. (2020). Meio Ambiente e Humanidade: O que temos a (re)aprender?.

https://www.ecodebate.com.br/2020/04/02/coronavirus-meio-ambiente-e-humanidade-oque-temos-a-reaprender-artigo-de-wendell-andrade/. 
Bar-On, Y. M., Phillips, R., \& Milo, R. (2018). The biomass distribution on Earth. Proceedings of the National Academy of Sciences of the United States of America, 115(25), 6506-6511. https://doi.org/10.1073/pnas.1711842115

Bruhn, F. R. P. Cadeia epidemiológica. (2016). Recuperado de: https://wp.ufpel.edu.br/ccz/files/2016/03/aula-cadeia-epidemiologica-6.pdf.

Cascella, M., Rajnik, M., Cuomo, A., Scott, C., Dulebohn, Di Napoli , R. Características, avaliação e tratamento do coronavírus (COVID-19). Recuperado de: https://www.ncbi.nlm.nih.gov/books/NBK554776/.

Chaves, T. S.S., \& Bellei, N. (2020). SARS-CoV-2, o novo Coronavírus: uma reflexão sobre a Saúde Única (One Health) e a importância da medicina de viagem na emergência de novos patógenos. Revista de Medicina, 99(1).

Cheng, V.C.C.; Lau, S.K.P.; Woo, P.C.Y., \& Yuen, K.Y. (2007). Severe acute respiratory syndrome coronavirus as an agent of emerging and reemerging infection. Clinical Microbiology Reviews 20(4): 660-694.

Cueto, M. O que um historiador da saúde tem a dizer sobre a pandemia do novo coronavírus (Covid19)? [Entrevista concedidad a Leal, B]. Café História - História feita com cliques. Recuperado de: https://www.cafehistoria.com.br/umhistoriador-da-saude-fala-sobre-novo-coronavirus/. Publicado em: 30 mar. 2020.

Ecodebate. A desobediência a Gaia e a COVID-19. Recuperado de: https://www.ecodebate.com.br/2020/04/01/a-desobediencia-a-gaia-e-a-covid-19-artigo-deeloy-f-casagrande-jr/.

Fioratti, C. $O$ que são os mercados chineses de animais silvestres?. Recuperado de: https://super.abril.com.br/sociedade/o-que-sao-os-mercados-chineses-de-animais-silvestres/

Freitas, A. A., Neto, D. D. S. V., \& Takenaka, E. M. M. (2017). Fluxo migratório da população rural jovem da região de Presidente Prudente-SP. Periódico Eletrônico Fórum Ambiental da Alta Paulista. 13(5).

Lam, T.T.; Shum, M.H.H.; Zhu, H.C.; Tong, Y.G.; Ni, X.B.; Liao, Y.S.,...Guan, Y. 2020. Identifying SARSCoV-2-related coronaviruses in Malayan pangolins. Nature. 583(7815), pp. 282-285. doi: 10.1038/s41586-020-2169-0.

Lovelock, J. (2020). A vingança de Gaia. Editora Intrinseca.

Seneme, G. E., \& Rachid, B. R. (2019). Ecologia geral e aplicada. Editora Senac. São Paulo.

Walker, P., Whittaker, C., Watson, O., Baguelin, M., Ainslie, K., Bhatia, S., ... \& Cucunuba Perez, Z. (2020). Report 12: The global impact of COVID-19 and strategies for mitigation and suppression. Recuperado de: https://dsprdpub.cc.ic.ac.uk:8443/bitstream/10044/1/77735/11/2020-03-26COVID19-Report-12-Spanish.pdf 
Werneck, G. L; Carvalho, M. S. A Pandemia de COVID-19 no Brasil: Crônica de Uma Crise Sanitária Anunciada. Recuperado

de: https://www.googleadservices.com/pagead/aclk?sa=L\&ai=DChcSEwi8.

Alonso, W. J., Schuck-Paim, C., Ribas Freitas, A. R., Kupek, E., Wuerzius, C. R., Negro-Calduch, E., Fernandes, R. M., Cristo, E. B., Veiga, A. B. G., Giglio, R., Abrao, M. S., \& Pinheiro, S. F. (2020). Covid-19 em contexto: comparação com a mortalidade mensal por causas respiratórias nos estados brasileiros. InterAmerican Journal of Medicine and Health, 3, 1 - 21. https://doi.org/10.31005/iajmh.v3i0.93

Ministério da Saúde. (2020). Manejo de corpos no contexto do novo coronavírus COVID-19.

Ministério da Saúde. (2020). Protocolo de manejo clínico do coronavírus (COVID-19) na atenção primária à saúde.

Organização das Nações Unidas. (2020). PROGRAMA DAS NAÇÕES UNIDAS PARA O MEIO AMBIENTE-PNUMA. 6 fatos por coronavírus e meio ambiente. Recuperado de: https://ciclovivo.com.br/covid19/6-fatos-sobre-coronavirus-e-meio-ambiente/.

Organização Das Nações Unidas. Perspectivas da população mundial 2019. Recuperado de: https://population.un.org/wpp/Graphs/Probabilistic/POP/TOT/900.

Organização das Nações Unidas. População mundial deve chegar a 9,7 bilhões de pessoas em 2050, diz relatório da ONU. Recuperado de: https://nacoesunidas.org/populacao-mundial-devechegar-a-97-bilhoes-de-pessoas-em-2050-diz-relatorio-da-onu/.

Oliveira, W.K., Duarte, E., França, G.V.A., \& Garcia, L.P. (2020). Como o Brasil pode deter a COVID-19. Epidemiol. Serv. Saúde, 29 (2) https://doi.org/10.5123/S1679-49742020000200023.

Perrota, A. P. (2020). Serpentes, morcegos, pangolins e 'mercados úmidos' chineses: Uma crítica da construção de vilões epidêmicos no combate à Covid-19. DILEMAS: Revista de Estudos de Conflito e Controle Social. Reflexões na Pandemia, pp. 1-6.

Sansonetti, P. (2020). Covid-19 ou la chronique d'une émergence annoncée. Exposé, Collège de France, 18.

Silva, A. A. M. da. (2020). Sobre a possibilidade de interrupção da epidemia pelo coronavírus (COVID19) com base nas melhores evidências científicas disponíveis. Revista Brasileira de Epidemiologia, 23, e200021. Epub March 16, 2020.https://doi.org/10.1590/1980549720200021

Ventura, D. D. F. L., Ribeiro, H., Giulio, G. M. D., Jaime, P. C., Nunes, J., Bógus, C. M., ... \& Waldman, E. A. (2020). Desafios da pandemia de COVID-19: por uma agenda brasileira de pesquisa em saúde global e sustentabilidade.Cadernos de Saúde Pública, 36 (4), http://dx.doi.org/10.1590/0102-311X00040620.

Vianna, L. F. N. (2020). Antropoceno e o COVID-19: Uma era de integração ou de controle da Natureza?. Revista Brasileira de Meio Ambiente, 8(1). 


\section{COMO CITAR ESTE ARTIGO:}

Silva, M. R. de O., Nascimento, R. C. do., Amaral, A. R. P. (2020). Impactos socioambientais e a pandemia do novo Coronavírus. Holos. 36(5), 1-13.

\section{SOBRE OS AUTORES}

\section{R. DE O. SILVA}

Mestrado em Ecologia Humana e Gestão Socioambiental pela Universidade do Estado da Bahia - UNEB (20182020). Graduação em Ciências Biológicas pela Universidade Estadual de Alagoas - UNEAL (2013-2017).

E-mail: regina estudante@hotmail.com

ORCID ID: https://orcid.org/0000-0001-7443-2496

\section{R. C. DO NASCIMENTO}

Graduada em Ciências Biológicas pela Universidade de Pernambuco (1995), com especialização em Ciências Biológicas. Tem experiência na área de Biologia Geral, com ênfase em Biologia Geral. Graduada em Direito, pela UNEB - Universidade do Estado da Bahia- com especialização em Direito do Trabalho. Atualmente, mestranda em Ecologia Humana e Gestão Socioambiental pela Universidade do Estado da Bahia-UNEB.

E-mail: regclaudia1@hotmail.com

ORCID ID: https://orcid.org/0000-0001-9147-8613

\section{A. R. P. AMARAL}

Possui graduação em Jornalismo em Multimeios pela Universidade do Estado da Bahia (2008-2012), graduada em Pedagogia pela Universidade de Pernambuco (1998-2002) e mestrado em Ecologia Humana e Gestão Socioambiental pela Universidade do Estado da Bahia-UNEB (2018-2019).Graduada em Ciências Biológicas pela Universidade de Pernambuco (1995), com especialização em Ciências Biológicas. Tem experiência na área de Biologia Geral, com ênfase em Biologia Geral. Graduada em Direito, pela UNEB Universidade do Estado da Bahia- com especialização em Direito do Trabalho. Atualmente, mestranda em Ecologia Humana e Gestão Socioambiental pela Universidade do Estado da Bahia-UNEB.

E-mail: adzamarajua@gmail.com

ORCID ID: https://orcid.org/0000-0001-9031-6890

Pareceristas Ad Hoc: Vandervilson Carneiro e Kalyane Oliveira

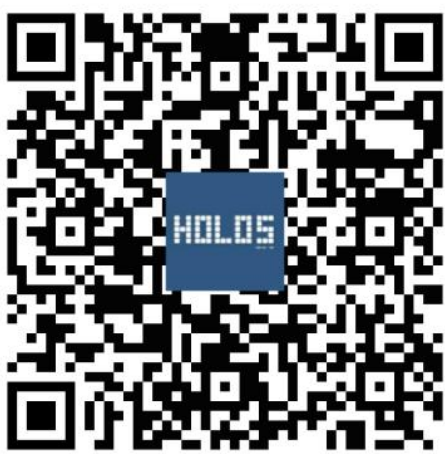

